\author{
Verónica Mafalda Nunes de Melo Policarpo \\ Universidade Católica Portuguesa, Lisboa, Portugal
}

\title{
Para lá da heteronorma: subjetivação e construção da identidade sexual
}

\begin{abstract}
Resumo Este artigo explora a construção da identidade sexual que não se enquadra na heteronorma a partir de um quadro teórico que articula três dimensões da experiência sexual: integração, estratégia e subjetivação. Argumenta-se que a formação destas identidades pode ser mais bem compreendida segundo o eixo da subjetivação e, mais particularmente, na tensão que se estabelece entre este e o da integração. Isto acontece porque, entre os indivíduos que vivem para além dos limites convencionais da heteronorma, a experiência sexual constróise, inevitavelmente, em confronto com a mesma, gerando uma reflexividade que contribui para operar um distanciamento do indivíduo face a papéis e valores convencionais, problematizandoos ou, mesmo, adotando modelos alternativos.

Palavras-chave: experiência sexual; identidade sexual; sexualidades fluidas; integração, subjetivação, heteronorma; identidades queer; sociologia da experiência.
\end{abstract}

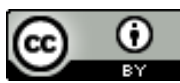

Esta obra está sob licença Creative Commons.

\section{Introdução}

Como se constrói o indivíduo, enquanto sujeito sexual, quando a sua experiência não se enquadra na heteronorma? Como define a sua identidade, em um processo dinâmico de permanente posionamento face aos quadros institucionais e normativos que prescrevem o comportamento sexual "aceitável"? Defendo, neste texto, que, nesse processo, é central a formação de um distanciamento crítico do ator em relação a papéis previamente instituídos, distanciamento esse que gera um tipo particular de reflexividade. É este o elemento central para a construção de uma identidade alternativa à heteronorma.

Para compreender este processo, recorro à sociologia da experiência, nomeadamente à teoria da experiência social de François Dubet (1994) e da sua proposta para definir o indivíduo contemporâneo como "dialógico" (2005): 
a um tempo social, racional e ético. Pretende-se compreender a experiência de gays e lésbicas partindo de uma aplicação desta teoria ao estudo da sexualidade, que propõe o conceito de experiência sexual (POLICARPO, 2011 a). Tal como o de Dubet, este conceito estrutura-se em torno de três dimensões: integração, estratégia, subjetivação, mas que assumem significados e modalidades específicas, no que se refere à sexualidade. O objetivo principal deste artigo é aprofundar como uma experiência construída em alternativa à heteronorma pode ser mais bem compreendida na tensão entre a adesão a papéis e valores integradores (eixo da integração, vg. na família, trabalho, comunidade etc.); e uma resistência e distanciamento crítico em relação aos mesmos (eixo da subjetivação), em que o ator reivindica, para si, um lugar emancipatório em um espaço social heteronormativo e potencialmente opressor.

O material empírico utilizado no presente artigo enquadra-se numa pesquisa mais ampla, realizada em Portugal, sobre a construção da experiência sexual em contextos de individualização das relações sociais. Foram recolhidas biografias sexuais de 35 indivíduos, 15 homens e 20 mulheres, entre os 30 e os 50 anos, residentes na área metropolitana de Lisboa, pertencentes às classes médias instruídas, com percursos de mobilidade social intergeracional ascendente ou estável. Os entrevistados encontravamse em diversos tipos de situação conjugal e familiar, identificando-se com diversas orientações sexuais. Dois entrevistados autoidentificaram-se como gays, quatro como lésbicas e dois como bissexuais. O objetivo do presente artigo é, a partir das suas histórias, aprofundar a construção da identidade sexual - um dos aspetos da experiência sexual, entendida de forma mais abrangente, segundo o conceito que referi e que apresentarei em detalhe mais adiante.

\section{Enquadramento teórico: da pertinência da sociologia da experiência para compreender a identidade sexual}

\section{Teoria queer e identidade sexual}

As questões da identidade sexual têm uma longa história na abordagem sociológica, tendo sofrido mudanças paradigmáticas importantes no século XX, ao longo do qual o casal heterossexual monogâmico se afirmou como norma do comportamento sexual (e da vida privada). A partir dos anos 80 , a historiografia gay colocou em causa a evidência desta categoria e desconstruiu a noção de heterossexualidade (v.g. KATZ, 1997; WEEKS, 1989; sob influência de GAGNON e SIMON, 1973; e FOUCAULT, 1994[1976]). Segundo 
'Em inglês, no original. Tradução livre.
Giami (1999), a própria noção de heterossexualidade inscreve-se num movimento de autonomização da função erótica da sexualidade, em relação à sua função reprodutiva, e, também, de normalização dessa função erótica. À medida que se dá a autonomização da função erótica da própria sexualidade, este movimento põe em causa, progressivamente, a heterossexualidade como categoria "normal".

É, sobretudo, a partir dos anos 90 , que a consideração de categorias identitárias relativamente estáveis (heterossexuais, gays, lésbicas) começa a ser questionada pela teoria queer, cujo foco se encontra, precisamente, na desestabilização do binómio heterossexual/homossexual e, consequentemente, da distinção dentro/fora que o mesmo implica. Baseando-se em pressupostos pós-estruturalistas e em autores como Foucault, Derrida ou Lacan, as teorias queer rejeitam a ideia de um sujeito homossexual "unificado", chamando a atenção, à boa maneira pós-estruturalista, para a inerente instabilidade da oposição homo/heterossexual. Estão assim lançadas as bases para a construção das identidades homossexuais como fluidas, não fixas, como resultado das tensões e fraturas internas da própria categoria (JAGOSE, 1996; ROSENEIL, 2000).

Esta ideia encontra-se presente, também, no conceito de fluidez ou sexualidades fluidas, um conceito desenvolvido nos estudos da sexualidade mas que não se enquadra teoricamente no campo da teoria queer. Lisa Diamond (2008) descreve-o como "uma flexibilidade na resposta sexual das mulheres, dependente da situação. Esta flexibilidade torna possivel para algumas mulheres experienciar desejos quer por homens, quer por mulheres, em determinadas circunstâncias, apesar da sua orientação sexual geral" (p. 3). ' Diamond utiliza, assim, o conceito exclusivamente para descrever a sexualidade feminina, como, aliás, muitos dos autores que, antes dela, a ele se referiram, direta ou indiretamente (2008, p. 8).

A este respeito, discutindo as diferenças entre perspectiva essencialista e construcionista, Diamond (2008, p. 17 e ss.) evoca, também, teorias para além das ciências sociais (biológicas, neurofisiológicas, psicológicas) para fazer o balanço dos conhecimentos sobre as diferenças de género no que diz respeito à sexualidade entre pessoas do mesmo sexo. Ou seja, a questão, para a autora, é compreender a que se devem tais diferenças de género, na experiência sexual entre pessoas do mesmo sexo, partindo, para isso, da premissa teórica de que essas diferenças existem efetivamente e que os processos de construção da orientação sexual são "fundamentalmente diferentes para mulheres e homens" ( $p$. 19). Coloca, também, a questão da própria natureza da homossexualidade feminina ser "fundamentalmente diferente" e pretende identificar "modelos sexuais específicos 
da sexualidade feminina" (p. 52).O pressuposto de que parto não deixa de ser, de certo modo, essencialista: o de que existe uma "natureza feminina", fundamentalmente distinta da masculina. Ao tentar desenvolver o argumento de que a sexualidade das mulheres é flexível, variável, fluida... não deixa de tomar "as mulheres" como uma categoria única e, logo, rígida (na medida em que se separa incomensuravelmente da dos "homens"). Assim, paradoxalmente, as sexualidades fluidas, apesar de traduzirem, de alguma forma, a desestabilização do binómio heterossexual/homossexual, acabam por reforçar o binómio feminino/masculino.

Estamos, portanto, longe do conceito de performatividade (BUTLER, 1990), segundo o qual a identidade de género é performativa, na medida em que decorre do discurso (v.g. sobre as características do que é feminino e masculino). É através de certas afirmações e sua repetição que a realidade e as diferenças de género são construídas. Decorre, também, de certos comportamentos repetidos, inscritos em scripts socialmente construídos e disponíveis; desta forma, o comportamento de género é roteirizado, ou seja, obedece a scripts. Desempenhando o comportamento previsto nos scripts (performance), os atores transformam esses atos na sua realidade, dia após dia. Neste sentido, o género não é uma expressão do que se é, mas do que se faz (BUTLER, 1990).

Tal como acontece com as categorias de género, também a identidade sexual pode ser vista como o resultado de uma construção instável, que põe em causa os compartimentos identitários, aproximando, de forma antes impensável, categorias até aí "opostas". Tal como masculino e feminino deixam de ser categorias fixas, mas, sim, uma condição (circunstancial) performativa, decorrendo do desempenho ou da ação repetida, o mesmo se passa com as categorias que pretendem descrever a identidade sexual, como heterossexualidade, homossexualidade, bissexualidade.

Esta desestabilização das categorias binárias ou, mesmo que não binárias, ainda assim potencialmente rígidas (como a de bissexualidade), é fundamental para compreender a diversidade de modos de construção das identidades sexuais contemporâneas. Porém, para interpretar os dados empíricos que recolhi sobre trajectórias sexuais em Portugal, no início do século XXI, não é possível abandonar totalmente a consideração da persistência do poder, real e simbólico, da heteronorma, enquanto categoria de análise. É esta que enquadra a realidade concreta dos indivíduos cuja experiência a desafia, de algum modo (e não exclusivamente por se definirem como LGBT, logo, para lá das categorias homo/ hetero). Uma experiência que se desenvolve a muitas "velocidades", em camadas sobrepostas e sucessivas de práticas e valores contraditórios, de sinal mais modernista ou,

544 Estudos Feministas, Florianópolis, 24(2): 541-562, maio-agosto/2016 
pelo contrário, mais tradicional; de impulsos de mudança social, mas, também, de focos de resistência a essas mudanças. Nestes contextos contraditórios e complexos, a experiência concreta de muitos indivíduos continua a definirse em relação a uma heteronorma imposta tácita e culturalmente. No entanto, não se pode dizer que esta constranja uniformemente todos os indivíduos, que a ela apenas "reagiriam" (acomodando-se ou, pelo contrário, revoltandose). Antes, são múltiplas as formas pelas quais os indivíduos negoceiam as suas identidades, perante um contexto heteronormativo que não pode descrever, nem explicar, a sua experiência. E é precisamente para melhor compreender este fenómeno que recorro à sociologia da experiência.

\section{Sociologia da experiência e concelto de "experiência sexual"}

São vários os autores que se debruçaram sobre a questão de saber como os indivíduos organizam, na sua vida quotidiana, a sua "personalidade social", confrontados que são com contextos (de socialização) múltiplos e contraditórios, que apelam a competências diferentes para esse trabalho identitário. A ideia central é a de que o ator se define por uma tensão entre lógicas de ação diferentes, que organizam a sua conduta. Alguns exemplos são Erving Goffman (1974) e os seus quadros de interação, conceito que descreve os princípios abstratos de organização que estruturam os acontecimentos; logo, a definição da situação por parte do ator e, consequentemente, o seu envolvimento subjetivo com a mesma; Luc Boltanski e Laurent Thévenot (1991), cuja noção de regimes de ação remete para disposições às quais os atores acedem, como parte de competências partilhadas, para formular os seus juízos e se posicionarem; ou François Dubet e o seu conceito de experiência social, que expressa a forma como os seres humanos organizam as suas condutas em torno de princípios estáveis, mas heterogéneos, definindo-se pela combinação complexa de várias lógicas de ação. Cada uma destas lógicas de ação remete para uma lógica do sistema social, já não concebido como um sistema único, mas, antes, como copresença de diversos sistemas estruturados por princípios autónomos. É esta proposta que inspira o conceito de "experiência sexual" usado neste artigo.

São três as lógicas da ação individual, segundo Dubet (1994). A integração, que descreve o modo como o ator se define pelas suas pertenças, visando mantê-las ou fortalecê-las, numa sociedade concebida como integração. A estratégia, que descreve o modo como o ator tenta realizar os seus interesses, numa sociedade concebida como um 


\begin{abstract}
2 Para uma explicação mais detalhada deste conceito e das suas implicações para compreender a sexualidade contemporânea, ver Policarpo, 2001 a e Policarpo, 2014.
\end{abstract}

mercado. Finalmente, a subjetivação, segundo a qual o ator se representa como um sujeito crítico, distanciando-se reflexivamente das identidades definidas a partir das duas outras lógicas, numa sociedade definida como um sistema de produção e dominação. Cada ator, individual ou colectivo, adota esses três registros de ação e articula-os, sendo que, na tensão entre eles é que se define a sua identidade.

É nestes termos da sua teoria da experiência que se desenha a figura do indivíduo contemporâneo, ${ }^{2}$ que, para Dubet, se constrói na tensão entre três dimensões distintas: social, racional e ética. A dimensão social descreve o trabalho de composição singular de um indivíduo que permanece, contudo, socialmente determinado.

As suas escolhas são feitas enquadradas em parâmetros que o ultrapassam, interiorizados ao longo da socialização. A dimensão racional resulta de uma inversão clara dos termos deste paradigma clássico, surgindo a sociedade como o resultado de múltiplas estratégias individuais, o efeito de uma composição de muitos indivíduos que orientam as suas condutas segundo estratégias racionais num contexto definido em termos de recursos e competição. Finalmente, a dimensão ética remete para a emancipação do indivíduo aos constrangimentos (sociais e racionais), que, assim, conquista a sua autonomia tornando-se um sujeito que é capaz de produzir um sentido para a sua vida, em um processo de constante reflexividade. O indivíduo contemporâneo está, pois, longe de uma versão puramente funcionalista, que o reduziria ao desempenho de papéis sociais, que, apesar de manterem a sua importância na primeira dimensão (social), não são a única fonte de construção da identidade, estando em tensão dialógica com as restantes dimensões.

Estes princípios da sociologia da experiência são, em meu entender, úteis para dar conta, sociologicamente, do modo como os indivíduos organizam a sua ação face à heterogeneidade de situações com que se defrontam ao longo da vida sexual. Nesses processos, vão construindo identidades que, como vimos, segundo a teoria queer e outras teorizações recentes no campo da sexualidade, escapam a categorizações apriorísticas, binárias e rígidas. Estas identidades são a expressão, a um nível micro, da dispersão e heterogeneidade dos princípios sociais e culturais que organizam as condutas individuais, a um nível mais amplo. Enquanto experiência social, a sexualidade nasce, justamente, da necessidade de articular, simultaneamente, diferentes lógicas de ação, que relacionam o comportamento e a vida sexual dos indivíduos com o sistema social em que estes se inserem. É a isto que se refere o conceito de experiência sexual. 
${ }^{3}$ Para um desenvolvimento do conceito, bem como dos ideaistipo de experiência sexual a que o mesmo permitiu chegar, ver Policarpo, 201 1a; Policarpo, 2014
Mas do que falamos, quando falamos em experiência sexual? E como pode esta ser útil à compreensão da construção das identidades de indivíduos LGBT?

\section{Objetivos e proposta: experiência sexual e identidades sexuais não hegemónicas}

O meu objetivo, no presente artigo, é, partindo dos pressupostos da sociologia da experiência, e, em particular, do conceito de experiência social de François Dubet, propor uma interpretação sobre os processos de construção das identidades sexuais contemporâneas, quando estas não se enquadram na heteronorma. Para isso, recorro ao conceito de experiência sexual, ${ }^{3}$ que, inspirado no de experiência social, comporta três lógicas de organização da experiência (integração, estratégia e subjetivação), que articulam a ação individual com os três sistemas sociais em que os indivíduos se movem (integração, mercado e cultura).

A lógica da integração diz respeito à abordagem da ação do indivíduo enquanto ser socialmente determinado por agentes e instituições socializadoras, que o constrangem, em maior ou menor grau, a adotar papéis e valores. A intensidade da adesão (forte, média ou fraca) a papéis sociais, valores, grupos e comunidades, nas várias dimensões da vida individual, permite-nos identificar diversas modalidades de viver essa pertença: convencional, marginal ou alternativa. A integração será de tipo convencional quando o indivíduo adere, sem distanciamento, a papéis e valores tradicionais herdados, sem os questionar. Será marginal quando o indivíduo aceita determinados termos dos papéis, valores e regras do grupo ou comunidade de pertença, mas não todos, e com condições. Será alternativa quando o indivíduo encontra novas formas de estar em "velhos" papéis (esposa, marido, pai, filho), ou reinventa mesmo novos papéis (muitos dos quais não têm nome; por exemplo, um papel entre o companheiro e o amante; alguém que desempenha "funções" parentais e educativas, mas sem laços ou papéis de parentesco definidos; por exemplo, um amigo).

Aestratégia remete para uma experiência desdobrada em dimensões como uma identidade-recurso, na qual distingo o jogador (seus recursos e finalidades) do jogo (suas regras e capacidade do ator para colocá-las em prática); a concorrência, na qual se distinguem os outros "jogadores" (Quantos são? Quais os seus recursos?), as oportunidades (identificadas e criadas) e os obstáculos (tudo o que coloca o ator em desvantagem na competição); finalmente, a componente fundamental para que a ação estratégica não se torne "racional" no sentido restrito, o poder, entendido enquanto capacidade para utilizar os próprios recursos para 
influenciar os outros. Estas dimensões concretizam-se em diversas áreas da vida do indivíduo: profissional, familiar, afectiva, sexual. As estratégias sexuais são limitadas quando são escassos ou fracos os recursos, finalidades, regras e capacidade de colocá-las em prática, oportunidades, outros atores em concorrência, e, ainda, a capacidade de usar os recursos a seu favor para influenciar outrem. Chamo de ocasionais ou ad hoc as estratégias que os atores compõem de modo cirúrgico, e, não, sistemático, irregular e, geralmente, de forma circunscrita no tempo, v.g. a um acontecimento particular (por exemplo, quando um indivíduo diversifica os seus parceiros sexuais, após uma separação de uma relação longa). Não chegam a ser diversificadas, mas ultrapassam os limites do tradicional. Finalmente, chamo estratégias diversificadas sempre que se verifica uma diversidade de recursos, finalidades, regras, jogadores, oportunidades e formas de uso do poder, em uma ou mais áreas da vida dos indivíduos, e, nomeadamente, na dimensão sexual. Tal como as estraté-gias limitadas correspondem a um grau de individualização mínimo, em que o indivíduo está predominantemente subordinado ao grupo (e, por isso, muito articulado com uma integração de tipo convencional), as estratégias diversificadas exigem um maior desprendimento do indivíduo da tradição, ou seja, um maior grau de individualização, e, por isso, se encontram mais articuladas com um tipo de integração alternativa.

A lógica da subjetivação permite completar o modo de formação plural da experiência sexual, na medida em que descreve os modos como os indivíduos se distanciam das identidades previamente definidas (integradoras ou recurso), aderindo a modelos alternativos de identidade. É possível identificar três modalidades de subjetivação, no que respeita à experiência sexual: padrão, problematizada e singular. Chamo de identidade padrão aquela que, para o indivíduo, se encontra "naturalizada". Ela não é objecto de questionamento (ou este é muito baixo) e aproxima-se da forma como é definida pelos papéis tradicionais. Chamo de identidade problematizada aquela que se produz quando o sujeito se questiona moderadamente face ao que lhe acontece, demonstrando alguma reflexividade, v.g. por força das circunstâncias (face a um turning point de grande impacto transformador na sua vida). Porém, não chega a conseguir distanciar-se completamente dos modelos tradicionais plasmados na sua identidade-integradora ou recurso. Como que fica a "meio caminho": entre estes que, submetidos ao teste das provas individuais, demonstram já não serem válidos para enquadrar a sua experiência; e a adesão a modelos alternativos, ou, mesmo, à construção de novos modelos. Finalmente, chamo de identidade singular 
aquela que o indivíduo constrói quando consegue distanciarse criticamente dos modelos tradicionais, dos papéis e valores por estes prescritos, e deles se emancipar.

De que forma podem, então, estas dimensões da experiência sexual ajudar-nos a compreender as formas de construção das identidades que não se enquadram na heteronorma?

\section{Para lá da heteronorma: uma experiência sexual "alternativo-singular"}

A análise das biografias sexuais recolhidas na investigação que serve de base ao presente artigo permitiu identificar uma modalidade da experiência sexual que pode ser descrita como "alternativo-singular", definindo-se pela tensão entre os eixos da integração e da subjetivação, na medida em que o sujeito se encontra fora da norma heterossexista da vida privada. O seu posicionamento no eixo da estratégia é secundário, podendo assumir modos limitados ou ocasionais, conforme os casos, mas como reflexo da conduta orientada pelas duas outras lógicas de ação. Caracteriza-se por um tipo de integração alternativa, uma identidade singular e estratégias limitadas ou ad hoc. A tensão entre as lógicas da integração e da subjetivação é norteada por uma forte orientação relacional e/ou conjugal: acima de tudo, os sentimentos envolvidos nas relações sexuais associam sexo e amor, e o seu maior sonho é construir uma relação duradoura. Porém, enfrentam este desafio, em um tempo caracterizado pela desinstitucionalização das relações familiares, sem o apoio das normas convencionais e institucionais. Porque a sua experiência se situa fora da norma da vida privada, a importância atribuída à orientação relacional da sexualidade sobressai ainda mais, pois não está "naturalizada", pelo contrário, tem de ser objeto de reflexividade, de questionamento e de construção crítica. É, pois, a partir desta tensão entre integração e subjetivação na construção da experiência sexual que podemos compreender melhor as identidades sexuais fora da heteronorma, que as categorias identitárias fechadas e rígidas deixaram de conseguir exprimir.

Identidades fluidas: "Se calhar este gostar já
não é um gostar assim tão normal como
seria de esperar entre duas pessoas amigas"

Ao longo da viagem biográfica do indivíduo, determinados pontos de viragem (turning points) podem assumir o significado mais profundo de um momento problemático do ponto de vista existencial, que pode mudar 
o curso de uma vida; nestes casos, podemos falar daquilo a que Norman Denzin (1989, p. 129) chama uma epifania maior, ou seja, momentos de grande intensidade, que tocam todas as dimensões da vida, com resultados imediatos e de longo prazo. Por exemplo, o amor (ou o apaixonar-se) surge, muitas vezes, como um turning point que confere à experiência sexual do sujeito uma intensidade e um significado diferentes das experiências em que sexo e sentimento surgem separados. Do mesmo modo, as relações sexuais podem constituir um turning point significativo de uma relação de amor préexistente.

Em ambos os casos, está interiorizada, pelos indivíduos, a "norma relacional", segundo a qual as relações sexuais, ainda que se tenham libertado da instituição do casamento como único locus legítimo, devem ser enquadradas por uma relação significativa. Esta "norma relacional", que se começou a consolidar a partir dos anos 80 , em Portugal (POLICARPO, 201 lb), está mais presente entre as mulheres do que entre os homens. Os estudos sobre comportamentos e valores têm demonstrado que a sexualidade masculina está mais orientada para a experiência e o prazer individuais, enquanto, na feminina, continua a prevalecer o sexo relacional. Deste modo, o amor e a paixão, enquanto epifanias maiores, assumem significados diferentes no masculino e no feminino. Podemos colocar a hipótese de que, no masculino, os casos em que sexo e amor vão juntos contribuem para reforçar uma orientação individualista da sexualidade: não põem em causa as práticas e os valores sexuais individualistas (v.g. diversidade de parceiro/as ao longo da vida, serial ou concomitante), ao mesmo tempo que não contrariam a norma relacional. Já, no feminino, o "apaixonar-se" e o amor surgem como elementos narrativos centrais das biografias sexuais das entrevistadas, incluindo as que vivem a sexualidade fora da heteronorma. Quando as experiências femininas são mais diversificadas (v.g. maior número de parceiro/as ao longo da vida, sequenciais ou paralelos), aproximando-se mais das masculinas, então o seu significado aproxima-se do de epifania maior que tem no masculino.

Primeira modalidade: "apaixonar-se como nunca antes" pela pessoa e não pelo seu género

Esta epifania maior pode assumir a forma de "apaixonar-se como nunca antes" por alguém do mesmo sexo, num modo fluido, que se caracteriza por uma entrada progressiva e sem contornos definidos em comportamentos fora da heteronorma, com uma grande incidência nos afetos. Neste modo de transição, para a construção de uma 
${ }^{4} \mathrm{~A}$ "amizade romântica" descreve a relação íntima entre duas mulheres, por exemplo, intelectuais, em que, pelo menos uma estava, muitas vezes, envolvida em movimentos feministas. Havendo ou não efectivo envolvimento sexual entre estas mulheres, não parece haver dúvidas de que esta "amizade romântica" constitui um estilo de vida lésbico bastante comum, em determinada época histórica, v.g. em finais do século XIX e princípios do século XX (SCHUYF, 1992). Um dos exemplos mais famosos, no meio literário, é o romance intenso que envolveu a famosa escritora Virginia Woolf e a aristocrata e também intelectual Vita Sackeville-West (figura que inspirou a sua personagem principal do romance Orlando). As cartas que Woolf escreve a Sackeville-West tal como certas partes do seu Diário Íntimo, dão testemunho da centralidade (e intensidade) dos sentimentos na construção desta experiência da sexualidade. identidade sexual não heteronormativa o indivíduo vai transitando das relações de amizade para as relações românticas e/ou sexuais. Trata-se de uma experiência predominantemente feminina que, por um lado, descreve a forma como as lésbicas vão tomando consciência de suaorientação sexual e a vão assumindo; ou, por outro, descreve a forma como a sexualidade feminina se expande para lá das categorias rígidas lésbica, bissexual, heterossexual, não se enquadrando nelas, com comportamentos e afetos variáveis ao longo do tempo e das fases da vida, revelando fluidez no comportamento sexual (DIAMOND, 2008) e, consequentemente, um questionamento do binómio hetero/ homossexual. Por um lado, esta experiência surge, sempre, na passagem de uma amizade romântica para uma relação de amor, ou de uma amizade (mesmo não sendo romântica) para uma atração sexual. É o caso de Manuela, 34 anos. Apesar de se autoidentificar como lésbica, Manuela iniciou a sua vida sexual de forma heteronormativa, "naturalizada". Ainda durante o primeiro namoro heterossexual longo (aos 18 anos), começa a ter contactos íntimos com uma amiga, de quem se foi aproximando cada vez mais. Era uma amiga de escola que acompanhou toda a história e que viria a ser o seu "primeiro amor". Tinham uma relação de amizade muito íntima, cada uma mantendo o respectivo namorado. Pode ser assim descrita como uma "amizade romântica", uma das formas mais características do amor entre pessoas do mesmo sexo, antes do século XX (SCHUYF, 1992, p. 61).4 A intimidade desta relação foi aumentando, até chegar ao contacto físico e sexual.

A nossa relação também foi evoluindo e foi-se tornando cada vez mais íntima, e houve muitos momentos em que, pronto, houve carícias, houve beijos na boca, houve algum contacto físico, houve inclusive envolvimento sexual, mas isso não foi ah... não fez nada questionar a minha orientação sexual, eu achei aquilo uma coisa que aconteceu e pronto [Manuela, 34 anos].

Esta relação não a fez, porém, questionar-se acerca da sua orientação sexual. Manuela associava a experiência àquela pessoa em particular, e não a uma orientação sistemática, duradoura ou exclusiva do seu desejo, para pessoas do mesmo sexo. A fluidez na relação íntima faz com que passem da amizade ao contato físico, sem se colocar, porém, a questão da identidade. Na época, esta experiência não a fez questionar a sua orientação sexual, pois não imaginou que o mesmo lhe pudesse acontecer com outras mulheres: "eu pensei que era aquela pessoa em especial, eu pensei que fosse por ser aquela pessoa em especial, eu pensei que, que era por ser ela, não por ser uma mulher, sim. Eu achei que ela é que era especial". 
Nesta fase da sua trajectória, a sua percepção é a de que está "orientada para a pessoa, e não para o seu género" (DIAMOND, 2008, p. 171 e ss.): é aquela pessoa em especial que desperta o seu interesse, e não as "mulheres em geral", enquanto categoria abstracta. Além disso, Manuela "nunca foi muito de se questionar", foi "mais de seguir os seus impulsos e os seus sentimentos" - o que aponta para uma naturalização da sua experiência e identidade.

Apesar de considerar que esta amiga foi o seu "primeiro amor", nunca foi uma relação assumida por nenhuma das partes. Apenas em termos de sentimentos o era:

Com essa minha amiga nunca houve, nunca houve uma relação assumida nem duma parte nem da outra, foi sempre uma coisa assim, quer dizer, havia assumir em termos dos sentimentos, disse-Ihe muitas vezes "eu amo-te" e ela disse-me a mim mas... nós achávamos que era assim tipo fraterno [Manuela, 34 anos].

O seu discurso revela a importância da existência de sinais socialmente partilhados para definir o desejo e, neste caso, a orientação sexual. Uma vez que os scripts sexuais hegemónicos disponíveis não contemplam esta fluidez, esta progressão, a sua integração pelo ator na sua experiência torna-se mais lenta e requer reflexividade. Apesar de não saber se chegou a estar "apaixonada" (não sentia "aquela urgência do desejo", "aquela falta de ar"), Manuela não tem dúvidas de que sentiu amor por essa amiga - o que remete para a centralidade dos afetos nesta modalidade fluida, de transição de uma amizade romântica para um relacionamento sexual. Nunca formalizaram uma relação, aliás, as duas continuavam com os seus respectivos namorados (tal como acontecia nas "amizades românticas" do início do século $X X)$.

A primeira pessoa, porém, por quem Manuela se "apaixonou", "no verdadeiro sentido da palavra", foi por aquela que viria a ser a sua primeira companheira. Tinha 22 anos e tratava-se de uma antiga colega de escola, da sua idade, por quem começou a sentir algo "que já não era normal". Até então, teve "um percurso bastante normal" ou "convencional", nas suas palavras (ou seja, namorados rapazes). Mas se apaixonar por uma amiga gerou reflexividade, conduzindo à redefinição da sua orientação: "Foi um dia, eu descobri, ah... Se calhar este gostar já não é um gostar assim tão normal como seria de esperar entre duas pessoas amigas. Isso levou-me a pensar e a questionar-me um bocadinho acerca disso". Apercebeu-se de que os seus afetos e desejo se orientavam, preferencialmente, para outras mulheres, definindo-se, então, como homossexual, "muito por uma questão afectiva, muito mais do que por questões

552 Estudos Feministas, Florianópolis, 24(2): 541-562, maio-agosto/2016 
sexuais". Desta "paixão", do sentimento, é que emerge, posteriormente, a consolidação de uma identidade lésbica.

A partir do momento em que se apaixona por alguém do mesmo sexo, a sua trajectória sexual segue um caminho até aí inesperado.

Houve coisas que eu não pude de maneira nenhuma planejar nem estavam nada nos meus programas, né? Pronto, não estava nada nos meus programas vir... eu sempre imaginei que ia ter uma vida, pronto, ia casar, ia ter uma vida como as outras pessoas, como a minha mãe, enfim, aquilo que é o tradicional. No entanto a minha vida deu uma volta e eu não estava nada à espera mas aconteceu. Hoje não estou nada aborrecida com isso, não é, não tenho nenhum tipo de frustração nem nenhum tipo de problemas em relação a isso [Manuela, 34 anos].

O facto de se apaixonar por uma mulher provoca, assim, uma mudança radical na sua vida, constituindo uma epifania maior, que excede, para o sujeito, o plano da escolha individual: "Em relação a mim, eu diria que não, não é uma escolha minha e agora a minha opinião pessoal é que isto não é uma escolha para ninguém!".

Desde que teve a sua primeira relação conjugal lésbica nunca mais voltou a se apaixonar nem a viver com alguém de sexo diferente. Contudo, embora a definição da sua orientação sexual seja clara para si, não põe, peremptoriamente, de lado, a possibilidade de se relacionar com alguém de sexo diferente. Distinguindo claramente a sexualidade da afetividade, associa a definição da sua orientação ao tipo de sentimento que consegue nutrir pelas mulheres, mas não pelos homens.

A história de Isabel [42 anos] dá-nos, igualmente, conta desta fluidez que se caracteriza por uma orientação para a pessoa, e não para o género. Tem uma iniciação sexual heteronormativa, com as primeiras relações sexuais com penetração aos 14 anos, com um rapaz de 19 anos. Aos 22 anos, resolve sair de casa, na sequência de (mais) um episódio de violência física da parte do pai. A sua transição para a vida adulta faz-se, assim, em dois momentos: um primeiro, em que vai viver sozinha para fugir à tirania do pai, em partes de casa, até conseguir alguma estabilidade financeira; um segundo, em que entra em conjugalidade com outra mulher.

Na minha vida é tudo muito estranho, porque tudo acontece assim muito espontaneamente, coisas tão à toa... (...) Nesse curtíssimo espaço de tempo em que eu trabalhei no bar, apaixonei-me perdidamente por uma colega, e ela por mim, tínhamos vinte e um, vinte e dois anos, mas assim uma loucura, uma coisa 
estúpida, eu já não vivia em casa dos meus pais, já estava a viver sozinha num quarto, e, foi quando eu fui morar com ela. Alugámos uma casa e foi lá que vivemos oito anos. Nós ficámos juntas dezoito [lsabel, 42 anos].

Se, por um lado, esta paixão lhe surge como "vinda do nada", um indicador de falta de sentimento de controle sobre a própria vida (baixa autonomia), por outro é o facto de já estar a viver sozinha (primeiro passo de individualização) que torna possível a imediata entrada em conjugalidade. Finalmente, trata-se de um coup-de-foudre, uma paixão compatível com o ideal de amor-paixão, que envolve relações de género desiguais em termos de práticas, embora não em termos de ideário - esse, sim, simétrico (GIDDENS, 1995, p. 41). No entanto, este modo "abrupto" de entrada num novo estilo de vida sexual, numa relação com alguém do mesmo sexo, não retira em nada a fluidez da experiência sexual: pelo contrário, sublinha-a. Senão, vejamos.

Na época muito envolvida emocionalmente por esta pessoa do sexo feminino, Isabel não deixou de se questionar sobre "quem era, afinal". Com uma educação muito rígida em termos de papéis e de moral sexual (restritiva), e com uma iniciação sexual heteronormativa, Isabel questiona-se sobre a sua identidade sexual.

Naquele período, porque eu ainda hoje isto me faz confusão, faz-me confusão... houve uma altura que eu não sabia o que é que eu era! Eu nunca me preocupei muito com rótulos e eu nunca me preocupei também com o que os outros possam pensar de mim, desde que eu esteja bem e esteja feliz. O que aconteceu naquela altura foi que eu me apaixonei por uma mulher, aconteceu, mas uma paixão uma coisa louca, de loucura, e ela também [lsabel, 42 anos].

A sua experiência aponta, assim, para uma sexualidade fluida, de alguém que se "se sente "atraído pela alma de outra pessoa, cujo embrulho é acidental"' (DIAMOND, 2008, p. 174). É o elemento epifânico da "paixão de loucura" que distingue, essencialmente, esta relação das outras, a que se acrescenta à sua duração (18 anos): a identidade lésbica vai-se construindo performativamente, ao longo do tempo, pela repetição de um sentimento e uma conjugalidade partilhadas no dia a dia, que engendram um distanciamento crítico e reflexivo do ator (eixo da subjetivação) em relação a papéis sexuais e de gênero previamente definidos, e hegemónicos, conforme a heteronorma (eixo da integração).

Se até aos vinte e um, vinte e dois anos eu andei com fulanos, ok, tive experiências traumáticas, muito traumáticas, se calhar por isso eu me apaixonei por uma mulher, achava eu.(...) Se calhar aquela paixão

554 Estudos Feministas, Florianópolis, 24(2): 541-562, maio-agosto/2016 
por uma miúda, pelo sexo feminino, fosse reflexo daquilo. Depois, comecei a achar que se calhar eu era homossexual, não é? Naquela altura eu não achava, mas dezoito anos a viver com uma mulher eu só podia ser homossexual, não? [lsabel, 42 anos].

Em contraste, a identidade sexual da companheira surge-lhe como prévia e rigidamente definida: "Já ela é mesmo homossexual", apontando para performatividades de género diferenciadas no seio do casal lésbico.

\section{Segunda modalidade: "experimentar", diversificar a experiência}

Em contraste com o que acaba de ser dito, existe uma outra modalidade de fluidez menos centrada nos afetos e mais na experimentação. Esta modalidade transparece, principalmente, no discurso das mulheres, jovens ou não, que desejam "experimentar" ter uma relação sexual com alguém do mesmo sexo. No seu caso, a identidade gay/ lésbica não está definida, muitas vezes nem sequer é questionada. Como nos relata Eva, neste momento, existe alguém "que está interessada" em si:

É uma jovem que está mortinha por experimentar... uma jovem, quer dizer, uma mulher de 36 anos. E achou que eu era a pessoa ideal para ela experimentar. Mas foi tão mecânica, tão desprovida de qualquer senso erótico, que a mim não me causou grande interesse, apesar de ela ser muito engraçada [Eva, 45 anos].

Para Eva, "estas coisas" são mais fáceis quando as pessoas são "mais novinhas", porque estão muito abertas a ter experiências novas e deixam-se fascinar, facilmente, por pessoas mais velhas. Tem experiência de parceiras mais novas, mas "nunca foi nada de amoroso, nada de envolvente". É visível um choque dos scripts interpessoais das intervenientes: de um lado, uma mulher "experimentalista", que deseja diversificar a sua experiência (eixo da estratégia), mas que falha na forma como põe o "jogo" em prática (muito "mecânica, desprovida de qualquer senso erótico"); do outro, uma mulher com bastante experiência sexual e homoerótica, para quem estas experiências não fazem sentido se não forem "amorosas e envolventes". Neste último script, prevalece a norma da afetividade como legitimadora da relação sexual.

As experiências sexuais fluidas descrevem, então, um modo de construção identitário em que os indivíduos (geralmente mulheres) estão abertos, ao longo da sua trajectória, e em diferentes contextos, a desenvolver uma relação íntima com alguém, independentemente do seu sexo/ gênero, sem, no entanto, estas transformações implicarem necessariamente uma mudança para uma "nova identidade 
sexual rígida" (v.g. de heterossexual a homossexual), nem uma autoidentificação como bissexual (cujo rótulo é duplamente estigmatizado, quer entre gays e lésbicas, quer entre heterossexuais por, como afirma Mendès-Leité [1996], colocar em causa a forma de categorização binária que atravessa a cultura ocidental).

Encontramos, por isso, manifestações dessa fluidez na experiência das mulheres que se autodefinem, desde o início da vida sexual, como heterossexuais, podendo ser casadas ou viver em conjugalidades heterossexuais, com ou sem filhos (crescidos ou não), e, que, mais tarde, se apaixonam e se relacionam com outra mulher. É o caso de Celeste [42 anos], que, após um casamento de 10 anos, se apaixonou por uma mulher, lésbica assumida desde sempre (que nunca teve um parceiro sexual masculino). Porém, para Celeste, então com 40 anos, a questão que se coloca é a mesma que se colocou no início a Manuela e, no final, a lsabel: significará esta relação uma mudança na orientação sexual (fixa e duradoura), ou, antes, uma experiência única que se dirige àquela pessoa em particular, e não às mulheres enquanto categoria abstracta? No seu caso, esta questão permanece em aberto, no momento desta investigação, sublinhando, também, o caráter dinâmico da construção identitária (em vários sentidos, incluindo o de sofrer transformações ao longo do curso de vida). Também a companheira de Manuela estava em situação semelhante: com mais de 30 anos, casada e com uma filha de 11 anos, nunca tinha tido nenhuma relação homossexual antes de se apaixonar por Manuela. Porém, por ela deixou o marido, com quem passou a partilhar a guarda da filha. A relação entre as duas duraria seis anos.

Na definição da experiência sexual fluida, vivida no feminino, destaca-se, principalmente, o papel dos afetos, da componente emocional: o amor, a paixão, o "apaixonar-se". O conceito de fluidez reproduz, assim, algumas clivagens tradicionais de género: experiências femininas relacionais, orientadas para a valorização dos afetos versus experiências masculinas individuais, orientadas para o prazer e experimentação. Esta reprodução é reforçada quando Lisa Diamond (2008) defende, na sequência de outros autores, o facto de ela ser uma experiência claramente feminina; mas, acrescentaríamos nós, em que o que está em causa é a performatividade de género (BUTLER, 1990). Ou seja, não se trata, principalmente, de uma experiência de "mulheres" (enquanto grupo homogéneo), mas de uma experiência que pode ser performatizada por qualquer indivíduo, incluindo homens, que se identifiquem com o género feminino. Do mesmo modo, quando, no âmago da experiência fluida, está o desejo de experimentação, de exploração dos sentidos, do desejo, do prazer e da experiência como valor em si mesma

556 Estudos Feministas, Florianópolis, 24(2): 541-562, maio-agosto/2016 
(como vimos anteriormente pelo caso de Eva), a experiência de mulheres (autoidentificadas como lésbicas, bisssexuais ou heterossexuais) e de homens aproxima-se, em torno de uma orientação individualista da sexualidade, orientada para o usufruto individual do prazer, em detrimento de uma orientação relacional.

\section{Identidades rígidas: "eu sempre gostei foi de mulheres"}

De uma forma totalmente diferente, Patrícia [E25, 36 anos], no momento da entrevista casada, com dois filhos e em processo de divórcio, afirma, peremptoriamente: "eu sempre gostei foi de mulheres". As "mulheres" surgem, no seu discurso, como categoria abstracta e, como é comum nestes relatos, Patrícia apercebeu-se da sua orientação sexual bastante cedo, "para aí aos dez anos", quando se apaixonou por uma colega de escola.

Nem percebi muito bem o que era, falei com ela, quer dizer, era uma coisa infantil, não é? Não, nunca fizemos nada, nem nada disso. Ela achou que eu estava maluca. (...) Aquelas coisas de miúdos, eu ainda chorei e tal, isto não pode ser, onde é que eu estou com a cabeça... está a ver? [Patrícia, 36 anos].

Falou, na ocasião, unicamente com a própria colega, com mais ninguém. Da mesma forma que, muito cedo, se apercebeu dessa "diferença"; desde logo teve presente que ela estava fora da norma. Após uma dolorosa rejeição, devida ao heterossexismo internalizado da sua namorada, Patrícia tentou "encaixar-se" na heteronorma. Começou por desvalorizar esse acontecimento, e iniciou, tal como em outros casos, um percurso predominantemente heteronormativo:

De certa forma desvalorizei [a experiência homossexual]. Assim, durante aquela fase, aquela coisa dos namoricos e não sei quê, era sempre com rapazinhos, não é? Quer dizer, sem sexo, não é? (...) de toda a gente, tinha uns namoricos [Patrícia, 36 anos].

Diferentemente dos casos que discutimos anteriormente, o discurso de Patrícia remete para uma identificação com categorias identitárias mais rígidas, tendo vivido grande parte do seu curso de vida de acordo com uma norma com a qual não se identifica (casamento heterossexual). O que não impediu esta dissociação clara entre práticas, por um lado, e identificação, por outro. No seu caso, o género é tomado, em si mesmo, como ponto de partida para a atração sexual, a própria noção de orientação sexual pressupondo que o género tem um papel fundamental para determinar se e quando uma pessoa se vai sentir atraída por outra (DIAMOND, 2008, p. 171). 
Esta perspectiva dá conta (ainda que insuficientemente) de identidades mais rígidas, cujos contornos estão previamente definidos e são, por isso, fortemente integradoras (dos quais são exemplos extremos os estereótipos do "macho latino", a "mulher feminina", a "lésbica butch" etc.). Por exemplo, quando Vitória [42 anos] afirma que nunca se sentiu atraída por um homem, nem nunca teve nem teria contatos sexuais com ninguém de sexo diferente do seu, adere, igualmente, a uma identidade lésbica rígida.

\section{Adesão a modelos coletivos alternativos à heteronorma}

A construção da experiência sexual não heteronormativa pode, também, caracterizar-se por um encontro de modelos culturais alternativos que conferem ao sujeito uma imagem positiva da homossexualidade, permitindo ao indivíduo "assumir-se" (fazer o coming ouf) em todas ou apenas algumas plataformas (família, trabalho, amigos, vizinhos) ou, mesmo sem esta revelação, viver a sua identidade sexual de forma politicamente activa. Aqui, os sujeitos aceitam o modelo alternativo que lhes é proposto, permitindo-se descobrir-se e "revelar-se na sua autenticidade". Ao mesmo tempo, confirmam a sua identidade não heteronormativa como positiva. Esta autenticidade constitui, aliás, uma das ideias centrais propostas pelos modelos identitários alternativos, por exemplo, nas campanhas das associações LGBT. Para além do indivíduo enquanto sujeito de direitos individuais e sexuais (à liberdade de expressão, de constituir família etc.), está em causa o seu direito a ser ele mesmo, a ser autêntico. O direito à autenticidade (e sua busca) constitui em si mesmo um modelo cultural alternativo que, cruzado com os discursos disponibilizados pelas associações LGBT e outros agentes sociais (agências governamentais, ONGs, meios de comunicação social), propicia às lésbicas, gays e bissexuais distanciar-se das identidades heteronormativas (fortemente integradoras) e construir modos alternativos e positivos de estar nos papéis.

É o caso de José Luís, 36 anos, que foi buscar esse modelo alternativo ao contacto com pessoas, nomeadamente um companheiro, com um capital cultural mais elevado que o seu. Por via do conhecimento histórico e da Arte, foi construindo uma visão positiva da homossexualidade, que lhe permitiu distanciar-se da forte identidade-integradora heteronormativa transmitida pela família e pelo grupo de pares, e viver a vida de acordo com a sua orientação sexual.

É também o caso de Andreia, 32 anos, que, após ter tido, como a maioria das mulheres lésbicas, uma iniciação heterossexual (e tardia, aos 24 anos, tendo em conta a média 
da respectiva geração, que se situa nos 18,5 anos (FERREIRAe CABRAL, 2010), se apaixonou por uma mulher com quem passou a viver uma intensa relação a distância. Porém, a sua identidade lésbica só se reforçaria, paradoxalmente, com dois importantes elementos integradores: por um lado, o choque aberto com a família de origem, nomeadamente com a mãe, que não aceitou a sua homossexualidade; por outro, o contacto e participação activa em grupos activistas dos direitos das pessoas LGBT. Deste modo, ao mesmo tempo que se distancia de uma identidade-integradora convencional (como filha, de quem era esperada uma acomodação a uma identidade heteronormativa), adere a novos papéis e valores (da comunidade LGBT), também eles constituindo uma forte identidade-integradora (ainda que alternativa à convencional). Na adesão total a esses papéis e valores, o sujeito poderá aproximar-se, não de uma identidade singular, mas, sim, de uma nova "identidade-padrão" (desta vez prescrita pelas comunidades e/ou associações LGBT).

Neste sentido, manter-se "dono de si próprio" significa manter um distanciamento crítico dessas dimensões integradoras, sejam elas oriundas de espaços sociais convencionais em termos de valores e práticas, ou de espaços sociais "alternativos" e politicamente engajados. Precisamente por isto, Andreia decidiu afastar-se do ativismo político e LGBT, embora, no seu dia a dia, continue a defender e pôr em prática as mesmas ideias.

\section{Entrada em conjugalidade: "senti que os acontecimentos me atropelaram um bocado (...) Em dois meses já estávamos a viver juntas"}

A construção da identidade sexual para lá da heteronorma surge, também, muito associada a uma entrada (quase) imediata na conjugalidade, na transição para a vida adulta. Mais uma vez, trata-se de uma experiência, sobretudo, feminina. Após uma grande paixão (vivida como uma "epifania maior"), que desperta, no sujeito, interrogações sobre a sua orientação sexual, podendo ou não redundar na assunção de uma identidade mais rígida (v.g. lésbica) ou mais fluida (v.g. não se identificar com nenhuma categoria), a passagem à relação sexual é quase imediata (poucos dias) e à conjugalidade também (cerca de um mês, por vezes menos, por vezes mais). Contrariamente à experiência masculina, que, muitas vezes, se caracteriza por um período de transição em que ambos os parceiros mantêm as suas casas (e até relacionamentos anteriores, ainda que já desprovidos de carácter sexual), passando à conjugalidade 
apenas mais tarde (por exemplo, no caso de José Luís, este período de transição estendeu-se por dois anos).

A rápida entrada na conjugalidade está presente na trajectória de todas as mulheres que se relacionaram com outras mulheres (autoidentificando-se ou não como lésbicas) e ocorre conforme um estilo de vida a que poderíamos chamar "normalizador", ou das "ordinary people". Parafraseando Schuytz (1992, p. 60), o que o caracteriza é o facto de "por um lado ser muito natural, mas por outro não ter grande importância", uma ideologia das pessoas comuns que seria prosseguida nos anos 50 pelas organizações de direitos das minorias sexuais.

Desse modo, está em causa a tensão entre o eixo da integração e o da subjetivação. Neste último, o indivíduo procura modelos alternativos (por exemplo, junto dos discursos socialmente disponíveis nos meios de comunicação social e difundidos pelas organizações de defesa dos direitos das minorias sexuais). Procura, primeiro, problematizar a sua identidade, e, depois, construí-la de forma singular. O paradoxo, porém, está em que, quanto mais ele aderir a tais discursos alternativos, menos a sua identidade será singular, e mais será padronizada - ainda que a partir de um padrão não heteronormativo. Ao mesmo tempo, naturalizando a sua experiência, afirmando como tudo foi tão "normal", "natural", o indivíduo tenta aproximar-se de uma identidade socialmente aceite. Facilita esse processo o facto de, no eixo da integração, aderir a papéis e valores característicos da norma da vida privada: o casal monogâmico e exclusivista assente na norma da fidelidade. Neste sentido, a sua integração em papéis seria quase convencional, não fosse a existência de uma intensa reflexividade que tornará a sua experiência diferente da heteronorma.

A história de Manuela fornece-nos pistas para reconstruir esta dimensão da experiência. $O$ marco que inaugura esta fase, em que passa a definir-se como homossexual, é, precisamente, a junção entre afetividade e sexualidade, associada a um forte sentimento de projeto, traduzido na coabitação.

Eu tenho recordações intensas daquele primeiro momento, do primeiro beijo, daquele primeiro contacto... depois o resto das coisas... senti que os acontecimentos me atropelaram um bocado, foi tudo assim tão rápido e tão repentino, aquilo foi: em dois meses já estávamos a viver juntas. E portanto foi tudo assim muito repentino [Manuela, 34 anos].

Este é, pois, um modo de entrada em novos papéis em que vários aspectos se sobrepõem na construção da experiência sexual do indivíduo: apaixonar-se, consciência mais clara da própria orientação sexual, (primeiras) relações

560 Estudos Feministas, Florianópolis, 24(2): 541-562, maio-agosto/2016 
sexuais com alguém do mesmo sexo e entrada na conjugalidade. O mesmo acontece com Isabel [42 anos], que, como vimos, se apaixona por uma colega de trabalho, aos 22 anos, inciando uma coabitação no mês seguinte (uma relação que duraria 18 anos)

\section{O heterossexismo internalizado: "aquele estigma que se lhe meteu na cabeça"}

Para Dawn Szymanski (2004, p. 145), o termo "heterossexismo internalizado" remete para uma instituição cultural opressiva de natureza sistemática e política, tendo em conta, simultaneamente, o sistema de género que oprime as mulheres lésbicas. Para a autora, as mulheres lésbicas e bissexuais podem experimentar o heterossexismo de modo distinto dos homens gays e bissexuais, devido a condições específicas que afetam a formação da sua identidade, tais como os efeitos de uma socialização em papéis de género femininos, e a experiência direta do sexismo nas suas vidas (SZYMANSKI, 2004, p. 146).

Efetivamente, um aspecto que se destaca na construção de algumas identidades sexuais para lá da heteronorma é não só a percepção do preconceito por parte de outros significativos (familiares, amigos), mas, também, a sua interiorização por via de uma educação heteronormativa. Ambos contribuem para a construção de uma experiência sexual em que a lógica da subjetivação entra em conflito com a da integração, na formação da identidade sexual.

É o que acontece com a primeira grande paixão de Manuela, uma amiga com quem tinha uma relação que se aproximava mais, como vimos, de uma "amizade romântica" (SCHUYF, 1992) e para quem a experiência íntima parece ter sido vivida em contradição.

Por causa de ela ser uma pessoa muito preconceituosa, acho que ela depois terá ficado com alguns problemas de consciência, ela chegou-me a falar nisso. Eu tentei desfazer-Ihe aquele estigma que se lhe meteu na cabeça, mas quer dizer, da experiência em si, eu sei que ela gostou. Ela depois ficava era sempre com aquelas coisas na cabeça, do "ai, isto não está nada certo, isto não está nada certo", pronto, essas coisas [Manuela, 34 anos].

A amiga provinha de uma família extremamente conservadora em termos de educação e valores e receava que a relação fosse descoberta: "ela dizia muitas vezes: "isto não me pode acontecer, isto não me pode acontecer"". Nunca chegaram a debater a questão da orientação sexual, porque, para a amiga, essa ideia era impensável. Acabaram por se separar, por Manuela não conseguir, nem desejar, "viver 


\footnotetext{
${ }^{5}$ Expressão da gíria juvenil que pretende descrever um jovem com ascendentes tradicionais $\mathrm{e}$ conservadores, geralmente oriundo de meios socio-económicos favorecidos. Este estereótipo associa-lhes a um certo estilo de vida e de lazer (favorecidos), código de vestuário, mas, também, de conduta.
}

mais na sombra" da relação heterossexual que a amiga continuava a manter. Neste caso, não se fez a transição da amizade romântica para a consolidação de um interesse afectivo e sexual exclusivo (lésbico).

O mesmo aconteceu com a segunda grande paixão de Patrícia. Após um desgosto de amor, entre os 15 e os 16 anos, confidencia o seu coração despedaçado a uma amiga que conhece nas férias e por quem se apaixona. Mais uma vez, esta amiga provém de um meio social e familiar conservador em termos de valores, o que fará com que a relação entre ambas seja estruturada no segredo, homofobia e heterossexismo internalizado pela amiga/ namorada.

Centrei-me, virei-me muito para essa outra amiga que conheci na praia. E pronto, ela era assim muito betinha ${ }^{5}$ e não sei quê e eu andei de volta dela, de volta dela, de volta dela e lá lhe dei a volta... E tivemos uma relação de 90 a 92, completamente escondida de todo o mundo, porque ela tinha pânico, pânico mesmo, que se soubesse (...) Pronto, ela disse sempre que gostava de mim e que fazia aquilo por mim, mas que não é... para já não era uma coisa que ela quisesse, era só por ser comigo. Ela nunca mais teve uma relação lésbica na vida, nunca, nunca tinha tido desejo antes, não teve depois, aquilo foi uma coisa isolada na vida dela, um bocado por pressão minha, porque era uma coisa que eu queria muito e ela, de certa forma, eu acho que foi uma forma de ela me manter como amiga dela, vá, deu-me aquilo em troca do que eu Ihe dava de cumplicidade e de afetividade [Patrícia, 36 anos].

É assim, na tensão entre o eixo da subjetivação e da estratégia, que se constrói esta parte da sua experiência: do seu lado, é principalmente a estratégia que está em causa, colocada ao serviço do reforço da sua identidade. Esta é, já, autoidentificada como lésbica, embora ainda de forma problematizada, pois o confronto com os modelos dominantes faz-se "a solo", sem ter propriamente na retaguarda modelos alternativos. A lógica da estratégia sobressai, aqui, na sua ação na medida em que Patrícia põe em cena uma identidade-recurso criando oportunidades e ultrapassando obstáculos (nomeadamente a resistência da amiga), conseguindo influenciá-la, usando, para isso, os seus recursos (diálogo, "cumplicidade", "afetividade"). Porém, o grande obstáculo com que se depara é o heterossexismo internalizado desta: é por isso que a lógica da subjetivação se torna relevante. Porque, se, para Patrícia, essa questão não se sobressai inicialmente, passa a colocar-se a partir da rejeição que sente desta namorada, com quem esteve até aos 20 anos. Sente-se abandonada e a repetição da rejeição 
faz com que ela passe a problematizar a sua identidade: "Desisti... De mulheres. (...) E entrei numa de que, não tenho esta - porque andava completamente para ali virada - não tenho esta, não quero mais nenhuma. Pronto". A rejeição da homossexualidade pela namorada impõe, assim, um rumo diferente à sua trajectória.

Pensei justamente que se calhar, se ela fosse outro tipo de pessoa eu teria assumido logo nessa altura e se calhar hoje a minha vida era completamente diferente. Acho que é isso basicamente. Eu teria assumido. Teria contado a toda a gente. (...) À família toda, aos meus pais, aos meus irmãos [Patrícia, 36 anos].

Esta foi, porém, uma vida que não viveu. Neste turning point, a sua vida toma outro rumo. O seu percurso sexual será uma tentativa de integração na heteronorma, nomeadamente pelo casamento heterossexual. Na sequência dos episódios da juventude, rejeita a homossexualidade e a relação heterossexual surge-lhe como a tentativa mais evidente de se "enquadrar" num modelo hegemónico: casamento com filhos. Neste sentido, a sua experiência passa a ser explicada, principalmente, pela tensão entre o eixo da subjetivação (rejeição conduz a uma identidade problematizada) e o da integração (passa de uma fraca a uma forte adesão a papéis e valores convencionais). O contexto social heteronormativo é interiorizado por Patrícia, que, desta forma, se aproxima de uma identidade-padrão pré-estabelecida pela heteronorma, afastando-se de uma identidade singularmente estruturada em modelos alternativos, como o direito à expressão livre dos seus desejos e orientação sexual. Como um círculo vicioso, esta adesão a modelos alternativos é bloqueada pelo preconceito internalizado, impedindo o sujeito de se questionar sobre a sua orientação sexual.

Também Eva precisou de se confrontar com a homofobia internalizada da sua primeira namorada, e que foi sua companheira durante seis anos, ao longo dos quais tentou esconder-se permanentemente dos olhares dos outros. Pelo fato de se "descobrir" gay aos 16 anos, em um meio rural, fechado, conservador e homofóbico, "lidou de forma dramática" com a sua homossexualidade. O heterossexismo internalizado, associado à discriminação, reforçou essa vivência negativa. No seu meio profissional correu o boato de que era lésbica, o que foi vivido de modo dramático, "imagine o que é numa terrinha daquelas, todos a olharem para verem se se via alguma coisa... (risos)". Sujeita à pressão, tentou afastar-se de Eva. "Todas as pessoas sabiam o que ela era, mas ela escondia-se, o que dava muito mais nas vistas (...) ah, não nos podem ver juntas, é melhor separarmonos...". Repare-se como, no seu discurso, se revela uma 
perspectiva essencialista da orientação sexual ("todas as pessoas sabiam o que ela era"). O contexto de pequeno lugar de província em que vivem é determinante para o desenvolvimento da relação, sendo o eixo da integração, articulado com o da subjetivação, o mais importante para explicar esta experiência (nomeadamente pela forma como o heterossexismo internalizado põe em risco essa integração).

\section{Notas finais}

Ao longo deste artigo procurei demonstrar que a construção de uma identidade sexual não hegemónica (lésbica, gay, bissexual ou de outro tipo) se faz na tensão entre duas dimensões centrais da ação individual: a integração (em papéis e valores de grupo, da comunidade etc.); e a da subjetivação (o modo como o sujeito se conquista a si mesmo, ao conseguir distanciar-se dessas identidades-integradoras). O elemento central, neste processo, é a reflexividade, desencadeada por um turning point determinante na biografia, que pode ser classificado como uma epifania (maior ou retrospectiva (DENZIN, 1989)), relativa à vida amorosa e sexual e que vem confrontar os indivíduos com o facto de o modelo hegemónico de vida privada não servir para interpretar a sua experiência sexual. Esse turning point implica uma experiência para lá dos limites das normas convencionais que regulam a esfera pessoal, desafiando, por isso, a integração do indivíduo em papéis convencionais.

No caso específico dos indivíduos que sentem atração por pessoas do mesmo sexo, esse turning point pode estar associado a diversos acontecimentos: primeiro desejo, primeira paixão, primeiro amor, primeira rejeição. No feminino, dá-se, frequentemente, de forma fluida - um processo de transição gradual da amizade à paixão e ao amor. Também mais frequentemente no feminino, a entrada imediata em novos papéis familiares (v.g. conjugais) exige dos indivíduos uma reinvenção desses papéis e o desenvolvimento de modalidades de integração alternativas às dominantes. $O$ preconceito e a rejeição de terceiros (família de origem, pares, ou, até, os próprios companheiros/as) constituem elementos decisivos na autointerpelação do sujeito, que se confronta com uma identidade socialmente desvalorizada, que é necessário gerir (GOFFMAN, 1973).Porém, em lugar de negar a sua experiência, conformando-se à heteronorma, vai fabricando identidades alternativas.

Considerando a orientação sexual em várias dimensões (comportamento, atração ou desejo, fantasias, preferência afetiva) e como um contínuo pleno de nuances (em lugar de estruturado em categorias rígidas), pretendi dar conta da diversidade e complexidade da construção da identidade sexual, enquanto processo ancorado no horizonte

564 Estudos Feministas, Florianópolis, 24(2): 541-562, maio-agosto/2016 
mais amplo de construção do indivíduo contemporâneo, balizado pelas noções de autenticidade, autonomia e realização pessoais, conforme o definiram autores como Charles Taylor (1998 e 2002), Ulrich Beck (2000 e 2005) ou François de Singly (2001 e 2005). Procurei, também, convocar para a reflexão os contributos da sociologia da experiência, colocando-os em diálogo com a teoria queer e outros conceitos relevantes da teoria da sexualidade. Uma das principais contribuições deste artigo é a tentativa de explicar as especificidades da construção de identidades para lá da heteronorma a partir do conceito de experiência sexual, demonstrando a importância dos processos dinâmicos através dos quais os atores se constroem como sujeitos sexuais, na tensão constante e simultânea entre diversas lógicas de ação. A tese central foi a de que, no caso das experiências para lá da heteronorma, a tensão essencial é entre a lógica da integração (o modo como o ator se integra em papéis e adere a valores socialmente definidos) e a da subjetivação (o modo como o ator deles se distancia criticamente, reclamando, para si, um espaço identitário reflexivo e alternativo, assim se constituindo também como um sujeito ético).

Importa, finalmente, sublinhar que o distanciamento crítico do autor, que gera reflexividade - central no meu argumento - não é exclusivo dos indivíduos que vivem para lá da heteronorma (lésbicas, gays, bissexuais). A questão central não está, assim, principalmente na orientação sexual, mas no modo como a experiência da sexualidade se enquadra, ou não, nos valores e normas hegemónicos contemporâneos, relativos ao comportamento sexual. Deste modo, todos os indivíduos que passaram por experiências que puseram à prova, contestando esses valores e normas convencionais, são, também, protagonistas de um processo de reflexividade que contribui para deles se distanciarem e se constituírem como sujeitos.

\section{Referências}

BECK, Ulrich e BECK-GERNSHEIM, Elizabeth. Individualization, institutionalized individualism and its social and political consequences. London: Thousand Oaks e New Delhi; Sage, 2005.

BECK, Ulrich. "A reinvenção da política". In: BECK, Ulrich; GIDDENS, Anthony e LASH, Scott. Modernização reflexiva. Política, tradição e estética no Mundo Moderno. Oeiras: Celta, 2000.

BOLTANSKI, LUC e THÉVENOT, Laurent. De la justification. Économies de la grandeur. Paris: Gallimard, 1991.

BUTLER, Judith. Gender trouble. New York and London: Routledge, 1990. 2004

Undoing gender. New York and London: Routledge, 
DENZIN, Norman. Interpretive interactionism. Newbury Park, London; New Dehli: Sage, 1989.

DIAMOND, Lisa. Sexual fluidity. Understanding women's love and desire. Harvard University Press, 2008.

DUBET, François. Sociologia da experiência. Lisboa: Instituto Piaget, 1994.

"Pour une conception dialogique de l'individu". Espaces Temps.net. Textuel, 21 jun. 2005. Disponível em: $<$ http://espacestemps.net/document1438.html>. Acesso em: 28 dez. 2006.

FERREIRA, Pedro Moura; CABRAL, Manuel Villaverde (Orgs.).; ABOIM, Sofia; VILAR, Duarte e MAIA, Marta (Col.). Sexualidades em Portugal: comportamentos e riscos. Lisboa: Bizâncio, 2010.

FOUCAULT, Michel. História da sexualidade - I. A vontade de saber. Lisboa: Relógio d’Água, 1994.

GAGNON, John e SIMON, William. Sexual conduct. The social sources of human sexuality. Chicago: Aldine Publishing, 1973.

GIAMI, Alain. "Cents ans d'hétérosexualité". Actes de Recherche des Sciences Sociales, n. 128, 1999, p. 38-45.

GIDDENS, Anthony. Transformações da intimidade. Sexualidade, amor e erotismo nas sociedades modernas. Oeiras: Celta, 1995.

GOFFMAN, Erving. Estigma. Rio de Janeiro: Zahar Editores, 1973.

. Frame analysis. An essay on the organization of experience. Boston: North eastern University Press, 1986.

JAGOSE, Annamarie. Queer theory: an introduction. New York: New York University Press, 1996.

KATZ, Jonathan Ned. "'Homosexual" and "Heterosexual". Questioning the terms". In: KIMMEL, M. e PLANTE, R. Sexualities: identities, behaviours and society. New York and Oxford: Oxford University Press, 2004, p. 44-46.

MENDĖS-LEITÉ, Rommel. Bissexualité. Le Dernier Tabou. Paris: Calmann-Levy, 1996.

PLUMMER, Ken (Ed.). Modern homosexualities, fragments of lesbian and gay experience. London and New York: Routledge, 1992.

. Telling sexual stories. Power, change and social worlds. London and New York: Routledge, 1995.

POLICARPO, Verónica. Indivíduo e sexualidade: a construção social da experiência sexual. Tese (Doutorado), Instituto de Ciências Sociais da Universidade de Lisboa, 2011 a. Disponível em: <http://repositorio.ul.pt/bitstream/10451/ 4197/1/ulsd061121_td_Veronica_Policarpo.pdf $>$.

. "Sexualidades em construção: entre o público e o privado". In: ALMEIDA, Ana Nunes de (Coord.). História da Vida Privada, v. IV, Lisboa: Círculo de Leitores, $2011 \mathrm{~b}$.

566 Estudos Feministas, Florianópolis, 24(2): 541-562, maio-agosto/2016 
Indivíduo e sexualidade: a construção social da experiência sexual. Lisboa: Imprensa de Ciências Sociais, 2014.

ROSENEIL, Sasha. "Queer frameworks and queer tendencies: towards an understanding of postmodern transformations of sexuality". Sociological Research Online, v. 5, n. 3, 2000. Disponível em: <http://www.socresonline.org.uk/5/3/ roseneil.html>

SCHUYF, Judith. "The company of friends and lovers. Lesbian communities in the Netherlands". In: PLUMMER, Ken (Ed.). Modern homosexualities, fragments of lesbian and gay experience. London and New York: Routledge, 1992, p.5364.

SILVA, Francisco Vieira da. Família, individualização e experiências da homossexualidade em Portugal. Tese (Mestrado em Ciências Sociais), Lisboa, Instituto de Ciências Sociais da Universidade de Lisboa (ICS-UL), 2006.

SINGLY, François de. "La naissance de l'individu individualisé et ses effets dans la vie conjugale et familiale". In : Être soi parmi les autres, famille et individualisation Tome 1, Paris: L'Harmattan, 2001.

L' Individualisme est un humanisme. Paris: Éditions de L'Aube, 2005.

SZYMANSKI, Dawn M. "Relations among dimensions of feminism and internalized heterosexism in lesbians and bisexual women". Sex Roles, v. 51, n. 3/4, agosto 2004, p. 145-159.

TAYLOR, Charles. Sources of the self: the making of the modern identity. Cambridge: Cambridge University Press, 1998.

. Le malaise de la Modernité. Paris: Les Éditions du Cerf, 2002.

WEEKS, Jeffrey. Sex, politics \& society. The regulation of sexuality since 1800. London \& New York: Longman, 1989.

[Recebido em 12/11/2015 e aceito para publicação em 09/12/2015]

Beyond Heteronormativity: Subjectivation and the Construction of Sexual Identities Abstract: This article explores the social construction of non-heteronormative sexual identities using as a theoretical framework the articulation of three dimensions of sexual experience: integration, strategy and subjectivation. It is argued that the formation of non-heteronormative identities can be better understood as a result of sexual subjectivation and, more particularly, of the tension between it and another important logic of sexual experience, integration. This happens because individuals that live beyond the conventional boundaries of heteronormativity build their sexual experience inevitably in conflict with such hegemonic norms, entailing a process of reflexivity that contributes to produce a distance between the Self and conventional roles and values, questioning them or even adopting alternative models.

Keywords: Sexual Experience; Sexual Identity; Sexual Fluidity; Integration; Subjectivation; Heteronormativity; Queer Identities; Sociology of Experience. 